\title{
Zum 70. Geburtstag des Herrn S. Karger
}

Am 21. Mai feierte Herr S. Karger seinen 70. Geburtstag. Als Zeichen ihrer Wertschätzung und in dankbarer Anerkennung seiner Ver-dienste als Verleger bedeutender medizinischer Zeitschriften und wert-voller medizinischer Werke haben die Herausgeber seiner Zeitschriften und die Autoren seines Verlages dem Jubilar auf Anregung von Herrn Geh. Rat Prof. Dr. Martin eine Sammlung handschriftlicher Adressen gewidmet. Herr Karger hat es verstanden, mit unermüdlicher Energie und weitem Blick seinen Verlag aus kleinen Anfängen zu einem Unternehmen von Weltruf zu entwickeln. Auch unsere Zeitschrift, die er 1899 mit Kuhnt und v. Michel gründete, wußte er bald den bereits· bestehenden bedeutenden ophthalmologischen Fachblättern ebenbürtig zur Seite zu stellen. "Wir wünschen von Herzen, daß es Herrn Karger vergönnt sein möge, der Wissenschaft auch weiterhin mit gleichem Er-folge und in unverminderter Frische und Schaffensfreude zu dienen,, Die Herausgeber.

Tagesnachrichten.

D. Der Vorstand der Deutschen Ophthalmologischen Gesellschaft hat be-schlossen die für Anfang August d. J. festgesetzte Versammlung auf das nächste Jahr zu 